\title{
PENGGUNAAN KARTU DOMINO UNTUK MENINGKATKAN HASIL BELAJAR LOGARITMA
}

\author{
NURSANTI IDAPITASARI \\ SMA Negeri 1 Bodeh Kab.Pemalang \\ Email : mevla2011@gmail.com
}

\begin{abstract}
ABSTRAK
Pembelajran matematika dari tingkat sekolah dasar sampai perguruan tinggi dianggap pelajaran yang sangat menakutkan. Mendengar kata matematika saja para peserta didik sudah merasa malas, takut. Matematika dianggap momok bagi para peserta didik. Tugas guru harus mencari cara agar pembelajaran menjadi efektif, efisien dan menyenangkan sehingga peserta didik merasa senang,nyaman dalam mengikuti pembelajaran. Guru harus bisa memilih media pembelajaran yang tepat, yang bisa menyampaikan pesan dengan baik. Dengan model pembelajaran discovery learning, dengan metode permainan kartu domino diharapkan dapat menciptakan pembelajaran yang menyenangkan. Peserta didik dapat belajar sambil bermain, sehingga dapat meningkatkan hasil belajar peserta didik pada pelajaran matematika materi logaritma. Penulisan best practice disusun dengan tujuan mendeskripsikan best practice penulis dalam menerapkan permainan kartu domino dalam pembelajaran logaritma. Untuk meningkatkan motivasi peserta didik sehingga dapat meningkatkan hasil belajar. Praktek terbaik dilaksanakan pada tahun pelajaran 2019/2020 yaitu pada bulan Oktober. Karya Tulis Ilmiah ini menggambarkan tentang peningkatan keaktifan dan hasil belajar peserta didik pada materi logaritma. Yang menjadi subyek dalam penelitian yaitu peserta didik kelas X MIPA 3, dengan perubahan yang signifikan, sebelum menggunakan permainan kartu domino keaktifan peserta didikk hanya $46,7 \%$ dengan memanfaatkan media kartu domino meningkat menjadi 76,7\% Demikian juga dengan hasil belajar sebelum menggunakan kartu domino rata - rata 55,33 setelah menggunakan kartu domino meningkat menjadi 75,33.
\end{abstract}

Kata Kunci : 1. Media 2. Kartu Domino 3. Hasil belajar 4. Logaritma

\section{ABSTRACT}

Learning mathematics from elementary school to college is considered a very scary subject. Just hearing the word math, the students already feel lazy, afraid. Mathematics is considered a scourge for students. The teacher's task must be to find ways to make learning effective, efficient and fun so that students feel happy and comfortable in participating in learning. Teachers must be able to choose the right learning media, which can convey messages well. With the discovery learning model, the domino card game method is expected to create fun learning. Students can learn while playing, so as to improve student learning outcomes in mathematics lessons on logarithmic material. Best practice writing is prepared with the aim of describing the author's best practice in applying the domino card game in learning logarithms. To increase the motivation of students so as to improve learning outcomes. The best practice is carried out in the 2019/2020 school year which is in October. This scientific paper describes the increase in student activity and learning outcomes on logarithmic material. The subjects in the study were students of class X MIPA 3, with a significant change, before using the domino card game the student's activity was only $46,7 \%$ by using the domino card media to increase to 76,7\%. Likewise, learning outcomes before using dominoes averaged 55.33 after using dominoes increased to 75.33 .

Keywords: 1. Media 2. Domino card 3. Learning outcomes 4. Logarithm

\section{PENDAHULUAN}

Dalam proses pembelajran ada 4 komponen yang mempengaruhi keberhasilan belajar siswa, yaitu bahan belajar, suasana belajar, media dan sumber belajar serta guru sebagai subyek pembelajaran (Mujiono, 1994). Guru sebagai subyek pembelajaran harus dapat memilih media 


\section{TEACHING : Jurnal Inovasi Keguruan dan IImu Pendidikan Vol. 1. No. 4 Desember 2021 e-ISSN : 2775-7188 | p-ISSN : 2775-717X}

dan sumber belajar yang tepat, membuat suasan belajar matematika terassa nyaman dan menyenangkan sehingga peserta didik dapat menerima pembelajaran dengan baik. Pada implementasinya di kelas, matematik mempunyai baanyak permasalahan karena disebabkan beberapa faktor, diantaranya dari peserta didik yang merasa takut dan malas terhadap matematika. Selain itu kurang tepatnya dalam memilih metode dan media pembelajaran yag sesuai dengan karakteristik materi.

Menurut Arsyad (2014) media pembelajaran adalah perantara yang berupa sumber belajar atau wahana yang mengandung materi instruksional yang dapat dimanfaatkan siswa untuk menunjang kegiatan belajar. Media pembelajaran dapat memperjelas penyajian pesan dan informasi sehingga dapat memperlancar dan meningkatkan proses dan hasil belajar. Prinsip pemilihan media pembelajaran menurut Harjanto (1997) yaitu: tujuan, keterpaduan, keadaan peserta didik, ketersediaan, mutu teknis, dan biaya.

Penyajian materi matematika yang dianggap membosankan, perlu kiranya diantisipasi dengan mencari alternative pembelajaran matematika yang disajikan secara inovatif, menarik, diminati dan mampu memotivasi peserta didik. Sehingga nantinya diharapkan bisa meningkatkan prestasi belajar peserta didik. Untuk menarik minat belajar peserta didik dan dapat berfikir kreatif dalam mempelajari materi

Terkait dengan peertimbangan pemilihan media pada best practice ini kartu domino dipilih sebagai media untuk menarik minat belajar peserta didik dan dapat berfikir kreatif dalam mempelajari materi Logaritma kelas X MIPA 3 SMA N 1 Bodeh. Walaupun permainannya relative sederhana tapi peserta didik dituntut untuk berfikir kreatif dan konsentrasi yang tinggi. Jika siswa mendapati suasana yang menyenangkan dalam proses pembelajaran, mereka akan terlibat total dalam proses pembelajaran itu. Keterlibatan secara total ini penting untuk melahirkan hasil akhir yang sukses, meningkatkan pemahaman konsep logaritma peserta didik. Cara Penggunaan Domino Logaritma Permainan ini dimainkan oleh 4 orang, guru merupakan pemandu permainan. Tugas guru disini adalah untuk mengecek apakah jawaban yang diberikan oleh pemain benar atau salah. Permainan ini tidak terikat dengan waktu. Permainan ini akan berhenti jika tidak ada lagi kartu yang bisa diturunkan. Peserta didik

Dengan permainan kartu domino logaritma tingkat pemahaman peserta didik tentang logaritma semakin meningkat. Hal ini bisa dilihat dari hasil test yang dipeoleh, bisa dibandingkan hasil test sebelum menggunakan kartu domino dan sesudah menggunakan kartu domino rata - rata yang diperoleh semakin meningkat. Hasil belajar merupakan komponen terpenting dalam pembelajaran. Perubahan tigkah laku adalah hasil belajar yang mencakup bidang kognitif, afektif dan psikomotorik (Dimyati dan Mudjiono :2006)

\section{METODE PELAKSANAAN}

Metode penelitian ini adalah best practice dengan metode pembelajaran discovery learning model permainan. Dengan kegiatan tahapan awal adalah pembelajaran secara konvensional. Pada tahap ini setelah pembelajaran peserta didik diberi soal evaluasi (pretest) untuk mengetahui daya tangkap atau pemahaman materi dari peserta didik. Pada tahap ke dua pembelajaran dilaksanakan dengan model permainan kartu domino.

Dengan metode permainan make at match, mencocokan kartu soal dan jawaban. . Peserta didik mencari kartu pasangan sambil belajar mengenai suatu konsep matematika dalam suasana yang menyenangkan, sehingga peserta didik akan lebih mudah memahaminya. Jumlah peserta didik tidak boleh terlalu besar, cukup teridiri dari 5 orang. Dengan tujuan agar proses kerjasama antar peserta didik efektif, sehingga semua anggota kelompok terlibat secara aktif dalam pembelajaran.

Penerapan model ini dimulai dari teknik peserta didik disuruh mencari pasangan kartu yang merupakan soal/jawaban yang diturunkan oleh peserta didik yang lain Peserta didik yang dapat memasangkan kartunya akan diberi poin.Demikian seterusnya samapi kartu habis. Pada tahap ke dua ini setelah pembelajaran peserta didik juga diberi soal evaluasi (post test). 
. Dari jejak pelaksanaan kegiatan yang telah dilalui diambil seperti keaktifan, ,ulangan harian (pree test dan post test) digunakan dalam best practice ini dan digambarkan dalam bentuk tabel.

Tabel 1. Aturan permainan kartu Domino

\begin{tabular}{|c|l|}
\hline No & \multicolumn{1}{|c|}{ Deskripsi } \\
\hline 1 & Permainan dilakukan di dalam kelompok yang terdiri dari 3 - 4 orang pemain \\
\hline 2 & Kocok kartu dan dibagikan 16 kartu sampai habis \\
\hline 3 & $\begin{array}{l}\text { Peserta diberikan waktu maksimal 5 menit untuk mengerjakan soal yang didapat } \\
\text { dahulu }\end{array}$ \\
\hline 4 & $\begin{array}{l}\text { Pemain utama ditentukan dengan undian. Jika jumlah kartu yang didapat tidak } \\
\text { sam banyak, pemain dengan jumlah kartu terbanyak mendapat giliran } \\
\text { mengeluarkan kartu terlebih dahulu }\end{array}$ \\
\hline 5 & $\begin{array}{l}\text { Pemain pertama diberi kebebasan untuk memasangkan :a) soal pada pasangan } \\
\text { jawaban,atau b) jawaban pada pasangan soal }\end{array}$ \\
\hline 6 & $\begin{array}{l}\text { Ketika kartu dikeluarkan, peserta lain wajib mencatat dan menghitung jawaban } \\
\text { dari soal tersebut }\end{array}$ \\
\hline 7 & $\begin{array}{l}\text { Pemain memasangkan kartu sedemikian rupa sehingga terdapat pasangan soal } \\
\text { dan jawaban yang tepat. Hal ini dilakukan terus menerus hingga seluruh kartu } \\
\text { habis. }\end{array}$ \\
\hline 8 & $\begin{array}{l}\text { Jika seluruh pemain tidak dapat menjawab ataupun merasa kesulitan,pemain yang } \\
\text { mendapat giliran berhak untuk melihat answer key dan mempelajari } \\
\text { jawabannya.setelah dipelajari, peserta diwajibkan untuk menerangkan pemain } \\
\text { lain yang belum mengerti }\end{array}$ \\
\hline
\end{tabular}

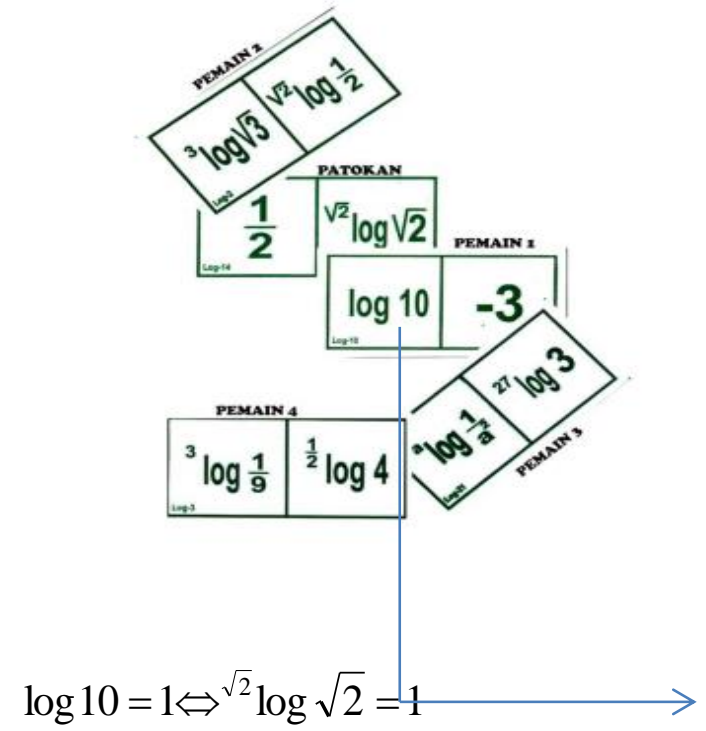

Kartu yang jadi patokan

\begin{tabular}{l|l}
$\frac{1}{2}$ & ${ }^{\sqrt{2}} \log \sqrt{2}$
\end{tabular}

Pemain 1 memasangkan kartu soal $\log 10=1$ nilainya sama dengan kartu soal

$$
{ }^{\sqrt{2}} \log \sqrt{2}=1 \text {, pemain } 2 \text { memasangkankartu soal } \frac{1}{2} \text { dengan kartu }{ }^{3} \log \sqrt{3}
$$

Best practice ini dilaksanakan di kelas X MIPA 3 berjumlah 30 siswa pada semester ganjil tahun pelajaran 2019/2020 yaitu mulai tgl 14 - 18 Oktober. Tempat pelaksanaan best practice adalah SMA Negeri 1 Bodeh. 
Model pembelajran konvensional dan metode ceramah yang digunakan dalam pembelajaran di kelas masih sering dijumpai interaksi peserta didik yang berbeda - beda . ada peserta didik yang antusias, langsung tertarik pada materi, ada yang hanya pasrah sekedar menerima, ada yang merasa takut dengan guru sehingga terpaksa menerima materi. Dengan kondisi yang demikian menuntut guru untuk bisa meningkatkan peran peserta didik sehingga tercipta pembelajaran yang aktif, inovatif, kreatif, efektif dan menyenangkan. Penerapan model pembelajaran permainan kartu domino untuk menciptakan pembelajaran yang aktif, inovatif, kreatif, efektif dan menyenangkan sehingga dapat meningkatkan motivasi dan semangat belajar peserta didik. Dengan model pembelajaran permainan kartu domino peserta didik lebih mudah dalam memahami materi , mereka bermain sambil belajar. Sehingga prestasi belajar peserta didik meningkat. Guru dituntut untuk bisa menciptakan suasan pembelajaran yang aktif,inovatif, kreatif, efektif dan menyenangkan sehingga tujuan pembelajaran bisa tercapai dengan meningkatnya hasil prestasi belajar peserta didik. Dalam pembelajaran penggunaan model pembelajaran yang inovatif, yang sesuai dengan kompetensi dasar materi pembelajaran sangat berpengaruh terhadap peningkatan hasil belajar peserta didik.

Pembelajaran logaritma di kelas X MIPA 3 dalam penelitian ini dilakukan dengan metode konvensional dan metode permainan kartu domino. Dengan metode knovensional tingkat keaktifan peserta didik masih rendah. Sehingga pada kelas X MIPA 3 pembelajrannya diubah menggunakan model permainan kartu domino.Hasil yang diperoleh cukup menggembirakan, keaktifan peseerta didik dalam pembelajaran meningkat Ini menunjukkan respon yang positif. Rata -rata dari hasil evaluasi juga meningkat.

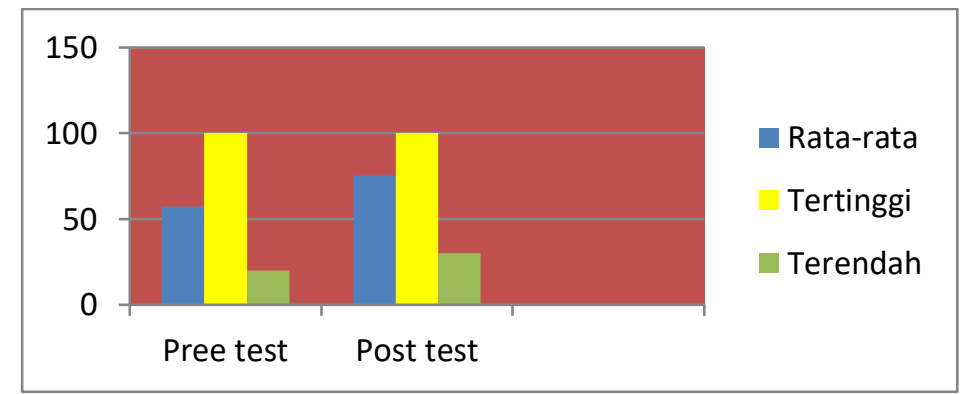

Gambar 1. Diagram data nilai test peserrta didik

Dari diagram 1 bisa kita lihat hasil tes peserta didik menggunakan metode konvensional (preetes) menunjukan nilai terendah yang diperoleh 20, rata - rata 55,33 dan nilai tertinggi 100. Dengan menggunakan metode permainan kartu domino logaritma hasil belajar yang diperoleh mengalami peningkatan yaitu, nilai terendah 30 , nilai rata - rata 75,33 dan nilai tertinngi 100

Tabel 1. Perbandingan Hasil Belajar Pree test dan Post test

\begin{tabular}{cllll}
\hline No. & \multicolumn{1}{c}{ Aspek Analisis } & $\begin{array}{c}\text { N. pree } \\
\text { test }\end{array}$ & $\begin{array}{c}\text { N. post } \\
\text { test }\end{array}$ & Keterangan \\
\hline 1. & Jumlah nilai & 1660 & 2.260 & Naik \\
2. & Nilai tertinggi & 100 & 100 & Tetap \\
3. & Nilai terendah & 20 & 30 & Naik \\
4. & Rata-rata & 55,33 & 75.33 & Naik \\
5. & Ketuntasan belajar & $56,66 \%$ & $86,66 \%$ & Naik \\
6. & Jumlah siswa yang tuntas & 17 & 26 & Naik \\
7 & Jumlah siswa yang tidak & 13 & 4 & Turun \\
\hline
\end{tabular}




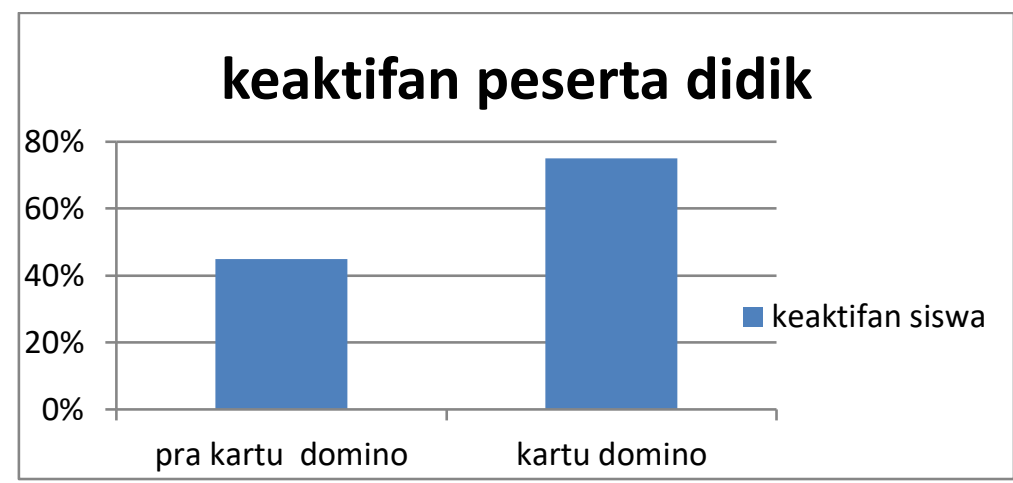

Gambar 2. Diagram data keaktifan peserta didik

Tabel 2. Perbandingan Keaktifan Belajar Pra Kartu Domino dan Kartu Domino

\begin{tabular}{ccc}
\hline Uraian & $\begin{array}{c}\text { Para kartu } \\
\text { domino }\end{array}$ & $\begin{array}{c}\text { Kartu } \\
\text { domino }\end{array}$ \\
\hline Jumlah & 14 & 24 \\
& $46,7 \%$ & $76,7 \%$ \\
\hline
\end{tabular}

Keaktifan peserta didik dapat dilihat dari diagram 2. Sebelum menggunakan kartu domino keaktifan peserta didik masih rendah. Hanya 46,7\% Peserta didik yang aktif dalam pembelajaran. Tetapi setelah menggunakan permainan kartu domino logaritma keaktifan peserta didik naik menjadi $76,7 \%$. Peserta didik banyak yang antusias dalam mengikuti pembelajaran.

\section{Pembahasan}

Media adalah segala sesuatu yang dapat digunakan untuk menyampaikan suatu pesan ( massage) dalam proses belajar mengajar sehingga dapat merangsang perhatian dan minat peserta didik (A.Cahyadi:2019). Pembelajaran adalah proses komunikasi antara pembelajar, pengajar, dan bahan ajar. Substansi dari media pembelajaran adalah bentuk saluran, yang digunakan untuk menyalurkan pesan, informasi atau bahan pelajaran kepada penerima pesan atau pembelajar dapat pula dikatakan bahwa media pembelajaran adalah berbagai jenis komponen dalam lingkungan dalam lingkungan pembelajar yang dapat merangsang pembelajar untuk belajar. Menurut Hamalik (1986) pemakaian media pembelajaran dapat membangkitkan keinginan dan minat yang baru,membangkitkan motivasi, dan rangsangan kegiatan belajar, dan akan membawa pengaruh-pengaruh psikologis terhadap siswa. Selain membangkitkan motivasi dan minat siswa, media pembelajaran juga dapat membantu siswa meningkatkan pemahaman, menyajikan data dengan menarik dan terpercaya, memudahkan penafsiran data,dan memadatkan informasi.

Keterkaiatan antara media pembelajaran dengan tujuan, materi, metode, dan kondisi pembelajar, harus menjadi perhatian dan pertimbangan pengajar untuk memilih dan menggunakan media dalam proses pembelajaran dikelas, sehingga media yang digunakan lebih efektif dan efisien untuk mencapai tujuan pembelajaran. Sebab media pembelajaran tidak dapat berdiri sendiri, tetapi terkait dan memiliki hubungan secara timbal balik dengan empat aspek tersebut. Dengan demikian, alat-alat, sarana, atau media pembelajaran yang digunakan harus disesuaikan dengan empat aspek tersebut, untuk mencapai tujuan pembelajaran secara efektif dan efisien.

Permainan kartu domino digunakan sebagai salah satu media dalam pembelajaran logaritma. Permainannya relatif sederhana namun setiap peserta didik tetap dilatih berfikir kreatif dan berkonsentrasi tinggi sehingga diharapkan prestasi belajar yang diperoleh meningkat. Cara Penggunaan Domino Logaritma Permainan ini dimainkan oleh 5 orang, guru merupakan pemandu permainan. Tugas guru disini adalah untuk mengecek apakah jawaban yang 5diberikan oleh pemain benar atau salah. Permainan ini tidak terikat dengan waktu. 


\section{TEACHING : Jurnal Inovasi Keguruan dan IImu Pendidikan Vol. 1. No. 4 Desember 2021 e-ISSN : 2775-7188 | p-ISSN : 2775-717X}

Permainan ini akan berhenti jika tidak ada lagi kartu yang bisa diturunkan. Manfaat Domino Logaritma. ialah membantu peserta didik dalam memahami pengoperasian dasar dari logaritma.

Hasil belajar merupakan bagian terpenting dalam pembelajaran.(Sudjana: 2009). Pendidikan yang berkualitas ditunjukkan dari hasil belajar peserta didik melalui proses pembelajaran. Pendidikan dikatakan berhasil jika proses pembelajaranberjalan sesuai tujuan perencanaan dengan baik yang ditunjukkan dengan adanya perubahan positif yang signifikan dalam pengetahuan, pemahaman, nilai dan sikap. Penggunaan kartu domino logaritma pada best practice yang dilaksanakan di SMA N 1 Bodeh dapat meningkatkan keaktifan peserta didik serta meningkatkan hasil prestasi belajar pesserta didik.

Keberhasilan penelitian best practice ini sejalan dengan hasil penelitian Iis Aprinawati (2017) yang menunjukkan media kartu domino bilangan mempunyai keistimewaan yaitu dapat mempermudah guru dalam mengajarkan suatu materi pelajaran matematika khususnya materi pecahan. .Media kartu domino bilangan juga merupakan salah satu media pendidikan yang berbasis media kartu permainan. Zoltan P. Dienes (Hudojo, 1990 : 51) menyatakan bahwa telah mengembangkan sistem pengajaran matematika dan berusaha agar pengajaran matematika menjadi lebih menarik serta lebih mudah untuk dipelajari, salah satunya adalah melalui media permainan, sehingga media kartu berupa permainan akan meningkatkan partisipasi aktif anak, dan pembelajaran lebih menarik.

Penggunaan kartu domino dalam pembelajaran sebelumnya telah dilakukan dalam penelitian yang dilakukan oleh ${ }^{1}$ Aulia Setyawati, ${ }^{2}$ Rahaju, ${ }^{3}$ Sri Hariyani(2019) yaitu Pembelajaran Operasi Pecahan dengan Model Make a Match dan Permainan Kartu Domino Pintar yang menyatakan pembelajaran menggunakan kartu domino pada kelas VIIF dapat meningkatkan pprestasi belajar peserta didik. Permainan juga meningkatkan daya tarik peserta didikuntuk mengerjakan soal dan menimbulkan kesenangan. Hal ini sesuai pendapat Sadiman, dkk (2014:23) bahwa penggunaan permainan memiliki beberapa kelebihan, yaitu menarik, menghibur, dan menyenangkan. Sadiman, dkk (2014:34) menambahkan bahwa pembelajaran dengan permainan berpotensi meningkatkan interaksi antarsiswa, sehingga pembelajaran tidak terpusat pada guru. Permainan memudahkan siswa memahami konsep serta membuat siswa lebih nyaman belajar matematika (Tukiran, 2017:189)

Dengan demikian dapat disimpulkan bahwa penggunaan kartu dominodapat dijadikan sebagai solusi atau akterbatif untuk mengatasi permaslahan keaktifan dan hasil belajar peserta didik dalam materi pelajaran apapun. Khususnya matematika yang sering ditakuti peserta didik.

\section{KESIMPULAN}

Penggunaan kartu domino dalam pembelajaran logaritma dapat meningkatkan keaktifan dan hasil belajar peserta didik, hal ini dapat kita lihat dari hasil data yang diperoleh . tingkat keaktifan peserta didik sebelum menggunakan permainan kartu domino 46,7\% dengan permainan kartu domino meningkat menjadi $76,7 \%$. Demikian juga dengan rata - rata hasil belajar yang diperoleh sebelum menggunakan permainan kartu domino 55,33\% dan setelah penggunaan kartu domino meningkat menjadi 75,33\%. Ini menunjukkan bahwa best practice yang dilaksanakan di SMA N1 Bodeh berdampak positif bagi peserta didik. Dapat memotivasi pesera didik untuk menaklukan matematika sehingga tidak ada kata takut akan matematika, bagi guru sebagai inovasi dan motivasi dalam mengemas pembelajaran yang kooperatif dan kreatif.

\section{DAFTAR PUSTAKA}

A.Cahyadi. (2019). Pengembangan Media dan Sumber Belajar: Teori dan Prosedur. Aprinawati , Iis. (2017). Penggunaan Media Kartu Domino Bilangan Untuk Meningkatkan Hasil Belajar Matematika Siswa Kelas V Sd . Jurnal Pelangi

Arsyad, A. (2011). Media Pembelajaran. Jakarta: Rajawali Press. 
Aulia Setyawati, Rahaju, Sri Hariyani. (2019). Pembelajaran Operasi Pecahan dengan Model Make a Match dan Permainan Kartu Domino. AKSIOMA: Jurnal Matematika dan Pendidikan Matematika Vol. 10, No. 2,

Dimyati dan Mudjiono. (2006). Belajar dan Pembelajaran. Jakarta: PT Rineke Cipta

Hamalik, O. (1993). Metode dan Kesulitan Belajar. Bandung: Tarsito.

Harjanto. (1997). Perencanaan Pengajaran. Jakarta: PT Rineka Cipta

Mujiono. (1994). Belajar dan Pembelajaran. Jakarta : Dirjen Dikti Depdikbud

Sadiman, dkk. (2014). Media Pendidikan: Pengertian, Pengembangan, dan Pemanfaatannya. Jakarta: Raja Grafindo Persada.

Sudjana, Nana (2009). Penilaian Hasil Proses Belajar Mengajar.Bandung : PT Remaja Rosdakarya

Tukiran. (2017). Penerapan Model Pembelajaran Teams Games Tournament Berbantuan Permainan Who Wants To Be A Millionaire. Math Didactic: Jurnal Pendidikan Matematika. 3(3), 188-198. DOI: 10.33654/math.v3i3.71 